\title{
Biotransformation of Glycosylated Saponins in Balloon Flower Root Extract into 3-O- $\beta$-D-Glucopyranosyl Platycosides by Deglycosylation of Pectinase from Aspergillus aculeatus
}

\author{
Jung-Hun Ju, Su-Hwan Kang, Tae-Hun Kim, Kyung-Chul Shin, and Deok-Kun Oh* \\ Department of Bioscience and Biotechnology, Konkuk University, Seoul 05029, Republic of Korea
}

\begin{abstract}
Platycodon grandiflorum root (Platycodi radix) saponins, platycosides, have been used as health supplements and food items for the treatment of respiratory disorders and pulmonary diseases. Deglycosylated saponins have been known to exert stronger biological effects than their glycosylated forms. In the present study, glycosylated platycosides in Platycodi radix extract were biotransformed into deglycosylated 3-O- $\beta$-D-glucopyranosyl platycosides, including 3-O- $\beta$-Dglucopyranosyl platycodigenin, 3-O- $\beta$-D-glucopyranosyl polygalacic acid, and 3-O- $\beta$-Dglucopyranosyl platyconic acid, by pectinase from Aspergillus aculeatus. This is the first report on the quantitative enzymatic production of 3-O- $\beta$-D-glucopyranosyl platycosides. The chemical structures of 3-O- $\beta$-D-glucopyranosyl platycosides were identified with LC/MS. Moreover, the biotransformation pathways of the three types of platycosides in Platycodi radix into 3-O- $\beta$-Dglucopyranosyl platycosides were established.
\end{abstract}

Keywords: Balloon flower root extract, platycosides, pectinase, 3-O- $\beta$-D-glucopyranosyl platycosides, biotransformation

Received: January 22, 2020 Accepted: March 10, 2020

First published online: March 13, 2020

*Corresponding author Phone: +82-2-454-3118 Fax: +82-2-444-5518 E-mail: deokkun@konkuk.ac.kr

Supplementary data for this paper are available on-line only at http://jmb.or.kr.

pISSN 1017-7825 elSSN 1738-8872

Copyright@ 2020 by The Korean Society for Microbiology and Biotechnology

\section{Introduction}

Platycodon grandiflorum A.DC. (Campanulaceae), commonly known as "balloon flower" or "bell flower," is a perennial flowering plant widespread in Northeast Asia. P. grandiflorum root (Platycodi radix) is used in the preparation of side dishes, desserts, teas, and flavored liquors. Platycodi radix extract is also widely used as a dietary supplement for the treatment of pulmonary diseases and respiratory disorders. The saponins (platycosides) in Platycodi radix extract exhibit diverse pharmacological activities, including anti-obesity [1], anti-inflammatory [2,3], anti-allergy [4], anti-oxidant [5], neuroprotective [6,7], and antitumor effects [8]. Platycosides in Platycodi radix extract are composed of pentacyclic triterpenes with two side chains. One of these side chains comprises the $\beta$-glucose residue, which is linked by a glycosidic bond at C- 3 in the aglycon, whereas the other side chain includes an oligosaccharide moiety (apiofuranosyl-xylopyranosyl-rhamnopyranosylarabinofuranosyl residue) attached to the ester linkage at C-28 (Fig. 1).

Deglycosylated saponins, which are obtained from the biotransformation of glycosylated saponins, exert stronger biological effects than their glycosylated forms $[9,10]$. The commercial enzymes snailase [11], laminarinase [12], and cellulase [13] convert deapiosylated platycoside E (deapi-PE) and platycoside E (PE) into deapiosylated platycodin $\mathrm{D}$ (deapi-PD) and platycodin $\mathrm{D}(\mathrm{PD})$ via deapiosylated platycodin $\mathrm{D}_{3}\left(\right.$ deapi- $\left.\mathrm{PD}_{3}\right)$ and platycodin $\mathrm{D}_{3}\left(\mathrm{PD}_{3}\right)$ by deglucosylation, respectively. The $\beta$-glucosidase from Aspergillus usamii converts PE into $\mathrm{PD}$ via $\mathrm{PD}_{3}[14]$. A crude enzyme from Aspergillus niger is known to convert $\mathrm{PD}$ into deapiosylated dexylosylated platycodin D (deapi-dexyl-PD) [15], while the $\beta$-glucosidase from Dictyoglomus turgidum converts PD into deglucosylated PD (deglu-PD) [16]. However, there is no report on the biotransformation by the hydrolysis of the oligosaccharide moiety at the C-28 position of platycosides to date. Although $3-O-\beta$-D-glucopyranosyl platycodigenin, 3-O- $\beta$-D-glucopyranosyl polygalacic acid, and 3-O- $\beta$-D-glucopyranosyl platyconic acid have been identified as the metabolites or saponins [17], no study has attempted in vitro enzymatic synthesis of 3-O- $\beta$ D-glucopyranosyl platycosides from glycosylated platycosides in Platycodi radix extract.

In the present study, glycosylated platycosides in Platycodi radix extract were biotransformed into deglycosylated platycosides by pectinase from Aspergillus aculeatus. After the biotransformation, the chemical structures of the deglycosylated platycosides were identified as 3-O- $\beta$-D-glucopyranosyl platycosides by LC/MS. 


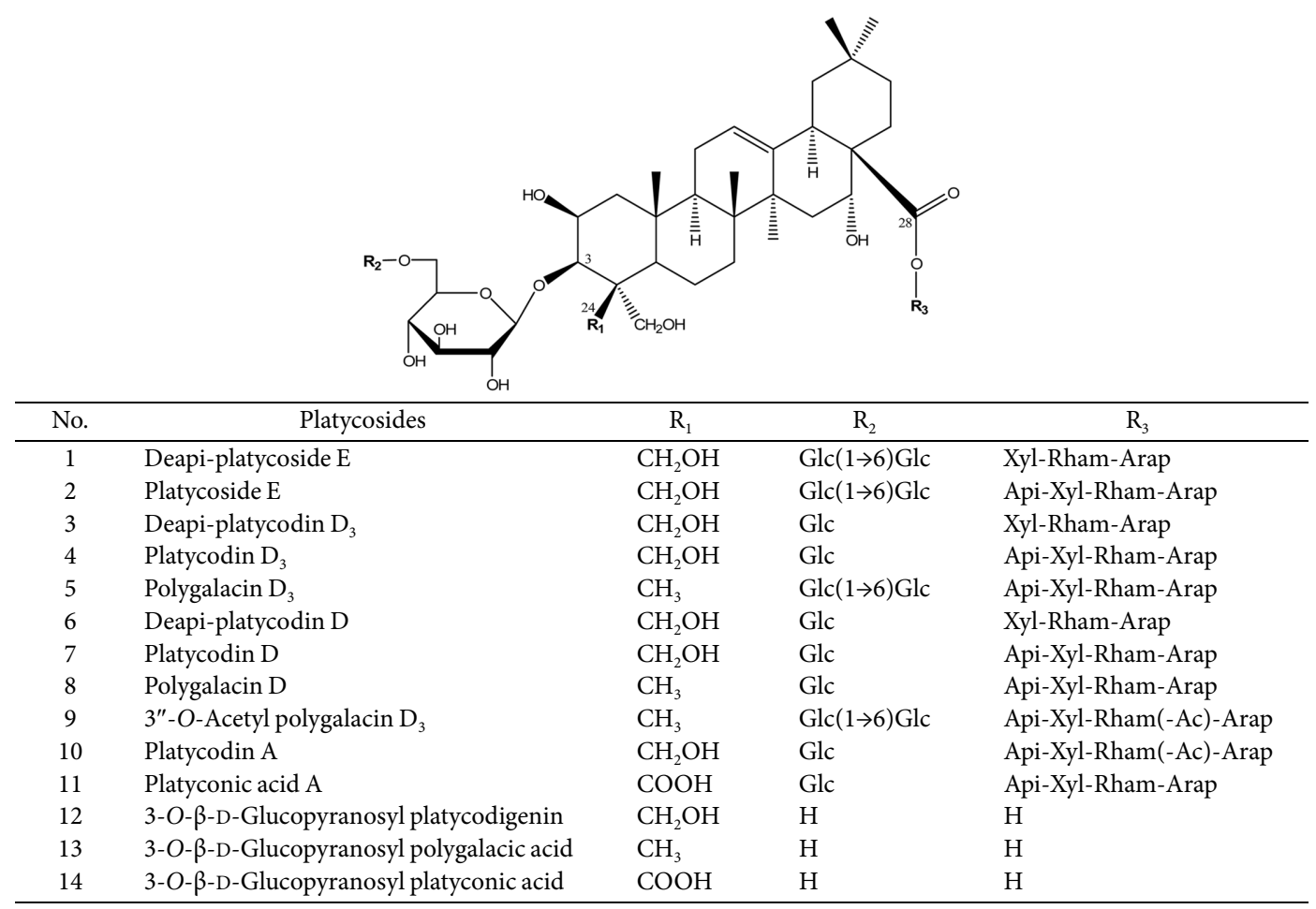

Fig. 1. Chemical structures of triterpenoid platycosides from Platycodi radix extract and platycosides obtained from the biotransformation with pectinase from A. aculeatus. Glycosylated platycosides from Platycodi radix extract are numbers 1-11. The products, 3-O- $\beta$-D-glucopyranosyl platycosides, are numbered 12-14. Glycosylated platycosides from Platycodi radix extract contain glycosides at C-3 and C-28. The glycosides at C-3 are Glc, Glc-Glc, and GlcGlc-Glc, while those at C-28 are Ara-Rham (or Rham(Ac))-Xyl-Api. Glc, $\beta$-D-glucopyranosyl-; Ara, $\alpha$-L-arabinopyranosyl-; Rham, $\alpha$-L-rhamnopyranosyl-; Xyl, $\beta$-D-xylopyranosyl-; Api, $\beta$-D-apiofuranosyl-; and Ac, acetyl.

In addition, the biotransformation pathways of glycosylated platycosides in Platycodi radix into 3-O- $\beta$-Dglucopyranosyl platycosides were investigated.

\section{Materials and Methods}

Materials

P. grandiflorum root was purchased from a local market (Republic of Korea). Platycoside standards, including deapi-PE, $\mathrm{PE}$, deapi-PD, $\mathrm{PD}_{3}$, polygalacin $\mathrm{D}_{3}, \mathrm{PD}$, and platyconic acid $\mathrm{A}$, were purchased from Ambo Institute (Republic of Korea), while pectinase from Aspergillus aculeatus as the commercial enzyme Pectinex Ultra SP-L was obtained from Novozymes (Denmark).

\section{Preparation of Platycoside Standards}

Platycodin A (PA), 3"-O-acetyl polygalacin $\mathrm{D}_{3}$, and deapi- $\mathrm{PD}_{3}$ standards were purified from glycosylated platycosides from Platycodi radix extract. To prepare 3-O- $\beta$-D-glucopyranosyl platycodigenin, 3-O- $\beta$-Dglucopyranosyl polygalacic acid, and 3-O- $\beta$-D-glucopyranosyl platyconic acid standards, the 3-O- $\beta$-Dglucopyranosyl platycoside product solutions were obtained from the reactions at $50^{\circ} \mathrm{C}$ with pectinase from $A$. aculeatus in $50 \mathrm{mM}$ citrate-phosphate buffer $(\mathrm{pH} 5.0)$ containing $10 \mathrm{mg} / \mathrm{ml}$ enzyme and $1 \mathrm{mg} / \mathrm{ml}$ of reagent-grade $\mathrm{PE}$, polygalacin $\mathrm{D}_{3}$, and platyconic acid $\mathrm{A}$ as substrates, respectively, after $24 \mathrm{~h}$. Platycodi radix extract and 3-O- $\beta$ D-glucopyranosyl platycoside product solutions were separated with preparative high-performance liquid chromatography (Prep-HPLC) (Agilent, USA) equipped with a Hydrosphere C18 prep column $(10 \times 250 \mathrm{~mm}$, $5 \mu \mathrm{m}$ particle size; YMC, Japan), eluted with water at $30^{\circ} \mathrm{C}$ at a flow rate of $4.7 \mathrm{ml} / \mathrm{min}$. The absorbance of the eluent was monitored at $203 \mathrm{~nm}$, and collected using a fraction collector. The peak area ratios of PA, 3"-O-acetyl polygalacin $\mathrm{D}_{3}$, and deapi- $\mathrm{PD}_{3}$ obtained from the purification of glycosylated platycosides from Platycodi radix extract to total area in HPLC chromatograms were approximately $90 \%$. The 3-O- $\beta$-D-glucopyranosyl platycosides showed $98 \%$ purity, as calculated from the ratio of the molar amount obtained after the purification of the products to the molar amount of the substrates.

\section{Extraction of Platycodi Radix}

The dried root of P. grandiflorum ( $100 \mathrm{~g}$ ) was suspended in 11 of $99.8 \%(\mathrm{v} / \mathrm{v})$ methanol and incubated at $80^{\circ} \mathrm{C}$ for $24 \mathrm{~h}$. After incubation, the precipitates were eliminated with vacuum filtration through a filter with a pore size of 
$0.45 \mu \mathrm{m}$. The methanol was removed by evaporation, and the dried residue was dissolved in 11 of water. The methanol-free solution was applied to a column containing Diaion HP-20 resin $(500 \mathrm{~mm} \times 12 \mathrm{~mm})$. Other hydrophilic compounds and free sugars were removed by washing the column with water, and the adsorbed platycosides in the resin were extracted by sequentially eluting with 21 of methanol at a flow rate of $0.5 \mathrm{ml} / \mathrm{min}$. The methanol in the extracted platycosides was removed by evaporation, and the dried residue was dissolved in 11 of water. The dissolved solution was diluted to $7.4 \%(\mathrm{w} / \mathrm{v})$ Platycodi radix extract by adjusting the concentration of PE to $1.0 \mathrm{mg} / \mathrm{ml}$, which was used for the biotransformation of platycosides.

\section{Biotransformation of Glycosylated Platycosides}

The biotransformation into 3-O- $\beta$-D-glucopyranosyl platycodigenin, 3-O- $\beta$-D-glucopyranosyl polygalacic acid, and 3-O- $\beta$-D-glucopyranosyl platycconic acid in the presence of $10 \mathrm{mg} / \mathrm{ml}$ of pectinase from A. aculeatus were carried out at $50^{\circ} \mathrm{C}$ in $50 \mathrm{mM}$ citrate-phosphate buffer ( $\mathrm{pH} 5.0$ ) with $1 \mathrm{mg} / \mathrm{ml}$ of reagent-grade $\mathrm{PE}$, polygalacin $\mathrm{D}_{3}$, and platyconic acid $\mathrm{A}$ for $24 \mathrm{~h}$, respectively. The biotransformation into $3-O-\beta$-D-glucopyranosyl platycosides was performed at $50^{\circ} \mathrm{C}$ in $50 \mathrm{mM}$ citrate-phosphate buffer $(\mathrm{pH} 5.0)$ containing $10 \mathrm{mg} / \mathrm{ml}$ enzyme and $7.4 \%(\mathrm{w} / \mathrm{v}$ ) Platycodi radix extract containing $1 \mathrm{mg} / \mathrm{ml} \mathrm{PE}, 0.05 \mathrm{mg} / \mathrm{ml}$ polygalacin $\mathrm{D}_{3}$, and $0.17 \mathrm{mg} / \mathrm{ml}$ platyconic acid A for $36 \mathrm{~h}$.

\section{Analytical Methods}

The reaction was terminated and exacted with $n$-butanol at a ratio of $1: 1$, resulting in the separation of components into $n$-butanol and water fractions. The $n$-butanol fraction was evaporated until complete dryness, and the dried residue was treated with methanol. The concentrations of platycosides were determined using the HPLC system (Agilent 1100) equipped with a Hydrosphere C18 column $(4.6 \times 150 \mathrm{~mm}, 5 \mu \mathrm{m}$ particle size, YMC, Japan), which was eluted at $30^{\circ} \mathrm{C}$ with a gradient of acetonitrile from $10 \%$ to $40 \%$ (v/v) for $30 \mathrm{~min}, 40 \%$ to $90 \%$ for $30-45 \mathrm{~min}, 90 \%$ to $10 \%$ for $45-50 \mathrm{~min}$, and $10 \%$ for $50-60 \mathrm{~min}$ at a flow rate of $1 \mathrm{ml} / \mathrm{min}$. All platycosides were quantified from the calibration curves constructed using standard solutions of 0.2 to $0.8 \mathrm{mg} / \mathrm{ml}$ platycosides in triplicates.

LC/MS analysis of platycosides was performed to identify the chemical structures using a Thermo-Finnigan LCQ Deca XP Plus ion trap MS (Thermo Scientific, USA) at the NICEM (Seoul National University, Republic of

\section{A}

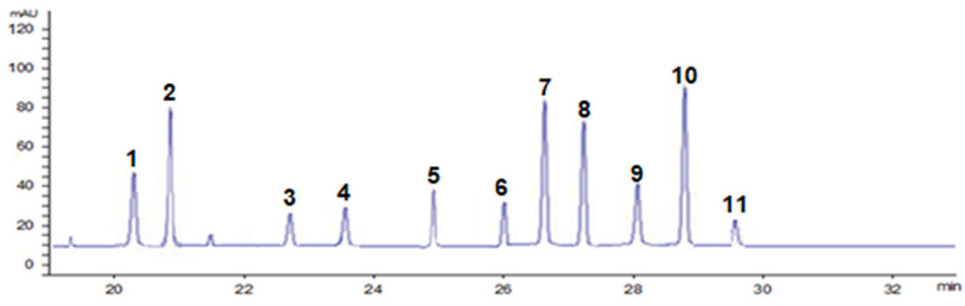

B

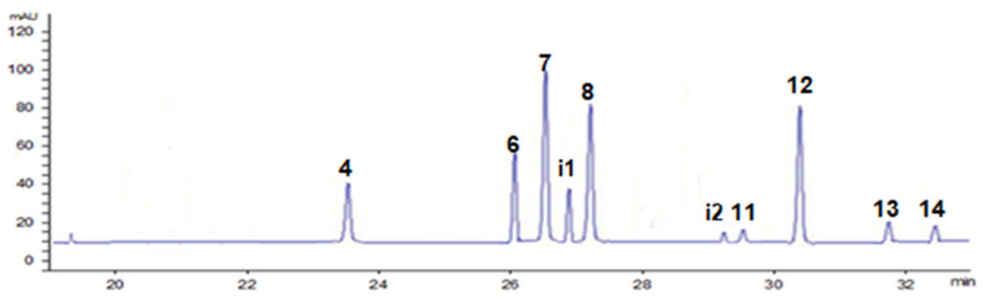

C

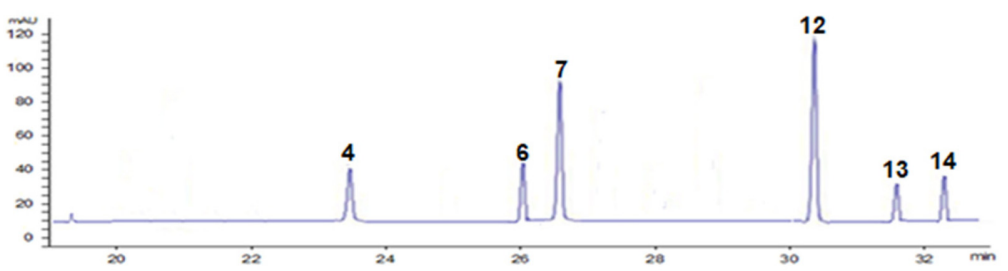

Fig. 2. HPLC chromatograms from the biotransformation of platycosides in $7.4 \%(w / v)$ Platycodi radix extract with pectinase from A. aculeatus. (A) Platycosides from Platycodi radix extract. Deapi-platycoside E (1), platycoside $\mathrm{E}(\mathbf{2})$, deapi-platycodin D3 (3), platycodin D3 (4), polygalacin $\mathrm{D}_{3}(\mathbf{5})$, deapi-platycodin $\mathrm{D}(\mathbf{6})$, platycodin $\mathrm{D}(7)$, polygalacin D (8), 3"-O-acetyl polygalacin $\mathrm{D}_{3}(\mathbf{9})$, platycodin A (10), and platyconic acid A (11). (B) Platycosides at $12 \mathrm{~h}$. Deapiplatycodin $\mathrm{D}_{3}(3)$, deapi-platycodin $\mathrm{D}(\mathbf{6})$, platycodin $\mathrm{D}(7)$, intermediate platycoside 1 (i1), polygalacin $\mathrm{D}(\mathbf{8})$, intermediate platycoside 2 (i2) polygalacin $\mathrm{D}(9)$, platyconic acid $\mathrm{A}(11)$, unknown product 1 (12), unknown product 2 (13), and unknown product 3 (14). (C) Platycosides at 36 h. Deapi-platycodin $\mathrm{D}_{3}(3)$, deapi-platycodin D (6), platycodin D (7), and unknown product 1 (12), unknown product $2(13)$, and unknown product $3(14)$. The biotransformation was performed at $50^{\circ} \mathrm{C}$ in 50 $\mathrm{mM}$ citrate-phosphate buffer ( $\mathrm{pH}$ 5.0) containing $10 \mathrm{mg} / \mathrm{ml}$ enzyme and Platycodi radix extract containing $1 \mathrm{mg} / \mathrm{ml} \mathrm{PE}, 0.05$ $\mathrm{mg} / \mathrm{ml}$ polygalacin $\mathrm{D}_{3}$, and $0.17 \mathrm{mg} / \mathrm{ml}$ platyconic acid $\mathrm{A}$ for $36 \mathrm{~h}$. 
Korea). The samples were ionized using electrospray ionization under the conditions of $275^{\circ} \mathrm{C}$ capillary temperature, 30 psi nebulizer gas, $5 \mathrm{kV}$ ion source voltage, $46 \mathrm{~V}$ capillary voltage in positive mode, $15 \mathrm{~V}$ fragmentor voltage in negative ionization mode, $0.01 \mathrm{~min}$ average scan time, $0.02 \mathrm{~min}$ average time to change polarity, and $35 \%$ abundant precursor ions at collision energy.

\section{Results and Discussion}

HPLC Analysis for Biotransformation of Glycosylated Platycosides from Platycodi Radix Extract by Pectinase The glycosylated platycosides, namely, deapi- $\mathrm{PE}(\mathbf{1}), \mathrm{PE}(\mathbf{2})$, deapi- $\mathrm{PD}_{3}(\mathbf{3}), \mathrm{PD}_{3}(\mathbf{4})$, polygalacin $\mathrm{D}_{3}(\mathbf{5})$, deapi-PD (6), $\mathrm{PD}(7)$, polygalacin $\mathrm{D}(\mathbf{8}), 3^{\prime \prime}$ - $O$-acetyl polygalacin $\mathrm{D}_{3}(\mathbf{9}), \mathrm{PA}(\mathbf{1 0})$, and platyconic acid A (11) from Platycodi radix extract were identified with HPLC at the same retention times of the standard platycosides (Fig. 2A). The biotransformation of the glycosylated platycosides from Platycodi radix extract into deglycosylated platycosides was performed with pectinase from A. aculeatus. In the HPLC chromatogram at $12 \mathrm{~h}$, deapi- $\mathrm{PD}_{3}(3)$, deapi-PD (6), PD (7), polygalacin D (8), platyconic acid A (11), intermediate platycoside 1 (i1) intermediate platycoside 2 (i2), unknown product 1 (12), unknown product 2 (13), and unknown product $3(\mathbf{1 4})$ were detected, whereas deapi-PE (1), $\mathrm{PE}(2), \mathrm{PD}_{3}(4)$, polygalacin $\mathrm{D}_{3}(5), 3$ "-O-acetyl polygalacin $\mathrm{D}_{3}(9)$, $\mathrm{PA}(10)$ were disappeared (Fig. 2B). In the HPLC chromatogram at $36 \mathrm{~h}$, polygalacin $\mathrm{D}(\mathbf{8})$, platyconic acid A (11), intermediate platycoside 1 (i1), and intermediate platycoside 2 (i2) were disappeared, whereas deapi- $\mathrm{PD}_{3}$ (3), deapi-PD (6), $\mathrm{PD}$ (7), unknown product 1 (12), unknown product 2 (13) and unknown product $3(\mathbf{1 4})$ were detected (Fig. $2 \mathrm{C})$. The reagent-grade $\mathrm{PD}_{3}(4)$ and deapi- $\mathrm{PD}(\mathbf{6})$ were completely converted into unknown product $1(\mathbf{1 2})$. However, $\mathrm{PD}_{3}$ (4) and deapi-PD (6) in Platycodi radix extract were not much decreased in Fig. 2 . The results may be due to the inhibition of the enzyme activity by other platycosides in Platycodi radix extract [18].

The total concentration of platycosides in $7.4 \%(\mathrm{w} / \mathrm{v})$ Platycodi radix extract was $2.76 \mathrm{mg} / \mathrm{ml}$, while the concentrations of PE, polygalacin $\mathrm{D}$, and $\mathrm{PD}$ as the main compounds were $1.00,0.80$, and $0.27 \mathrm{mg} / \mathrm{ml}$, respectively, corresponding to the contents of $36.2,29.0$, and $9.8 \%(\mathrm{w} / \mathrm{w})$ to total platycosides, respectively (Table 1$)$. After $36 \mathrm{~h}$, the concentrations of unknown product 1 (12), unknown product 2 (13), and unknown product 3 (14) were 0.61 , $0.21,0.1 \mathrm{mg} / \mathrm{ml}$, corresponding to the contents of $44.2,15.2$, and $7.2 \%(\mathrm{w} / \mathrm{w})$, respectively.

\section{Identification of Unknown Products Obtained after Biotransformation of Glycosylated Platycosides from Platycodi Radix Extract by Pectinase}

For identification of unknown products 1, 2, and 3, LC/MS analyses of these compounds were performed. The total molecular masses of unknown products 1,2 , and 3 were indicated by distinct peaks at mass per charge $(\mathrm{m} / \mathrm{z})$ 683.7, 667.2, and 697.6 $[\mathrm{M}+\mathrm{H}]^{+}$, respectively, in the LC/MS spectra (Fig. 2). Based on LC/MS data, the unknown products 1,2 , and 3 were identified as $3-O-\beta$-D-glucopyranosyl platycodigenin, $3-O-\beta$-D-glucopyranosyl polygalacic acid, and 3-O- $\beta$-D-glucopyranosyl platyconic acid, respectively.

In the previous studies, the glycosylated platycoside PE was converted into PD by $\beta$-glucosidase of $A$. niger [14] and into deglu-PD by $\beta$-glucosidase of $D$. turgidum [16]. PD was converted into deapi-dexyl PD by crude enzyme of $A$. niger [15]. In this study, the biotransformation of glycosylated platycosides in Platycodi radix extract into 3$O$ - $\beta$-D-glucopyranosyl platycosides by hydrolyzing oligosaccharide moiety (apiofuranosyl-xylopyranosylrhamnopranosyl-arabinofuranosyl) at C-28 was first reported.

Table 1. Platycoside content in $7.4 \%(\mathrm{w} / \mathrm{v})$ Platycodi radix extract before and after biotransformation by pectinase.

\begin{tabular}{clcccc}
\hline \multirow{2}{*}{ No. } & \multicolumn{1}{c}{ Platycoside } & \multicolumn{2}{c}{ Before reaction } & \multicolumn{2}{c}{ After reaction } \\
\cline { 3 - 6 } & & Content $(\%, \mathrm{w} / \mathrm{w})$ & Concentration $(\mathrm{mg} / \mathrm{ml})$ & Content $(\%, \mathrm{w} / \mathrm{w})$ & Concentration $(\mathrm{mg} / \mathrm{ml})$ \\
\hline 1 & Deapi-platycoside E & 36.23 & 0.07 & 0 & 0 \\
2 & Platycoside E & 0.36 & 1.00 & 0 & 0 \\
3 & Ddeapi-platycodin $\mathrm{D}_{3}$ & 1.45 & 0.01 & 0 & 0 \\
4 & Platycodin D & 1.81 & 0.04 & 0 & 0.10 \\
5 & Polygalacin D & 0.72 & 0.05 & 7.97 & 0.11 \\
6 & Deapi-platycodin D & 9.78 & 0.02 & 18.1 & 0.25 \\
7 & Platycodin D & 28.98 & 0.27 & 0 & 0 \\
8 & Polygalacin D & 5.80 & 0.16 & 0 & 0 \\
9 & 3"-O-Acetyl polygalacin $\mathrm{D}_{3}$ & 6.15 & 0.17 & 0 & 0 \\
10 & Platycodin A & 6.15 & 0.17 & $\mathrm{ND}$ & 0 \\
11 & Platyconic acid A & ND & ND & ND & ND \\
i1 & Iintermediate 1 & ND & ND & 44.20 & ND \\
i2 & Intermediate 2 & ND & ND & 15.22 & 0.61 \\
12 & Unknown product 1 & ND & ND & 7.24 & 0.21 \\
13 & Unknown product 2 & ND & 2.76 & 100 & 0.10 \\
14 & Unknown product 3 & Total & & &
\end{tabular}

ND: not detected. 
A

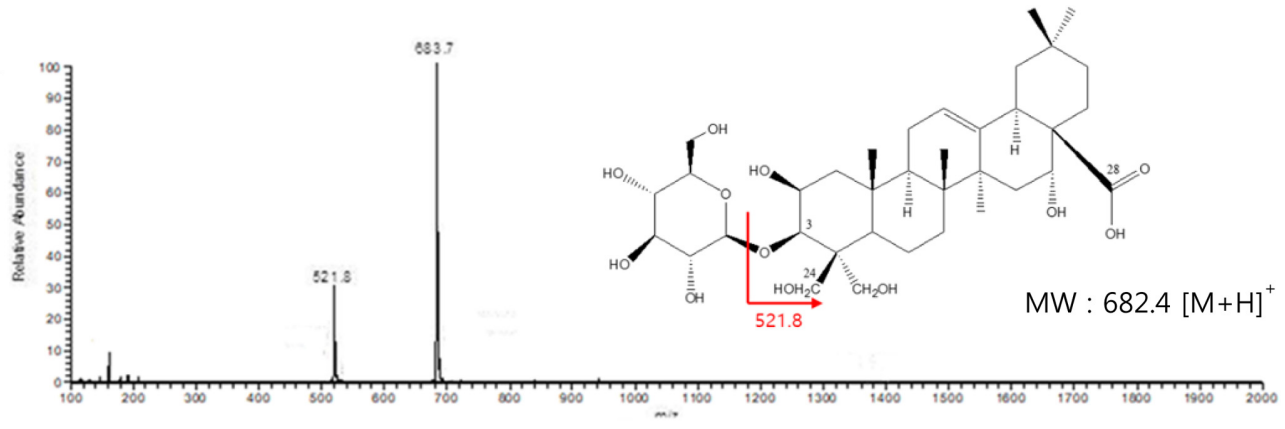

B

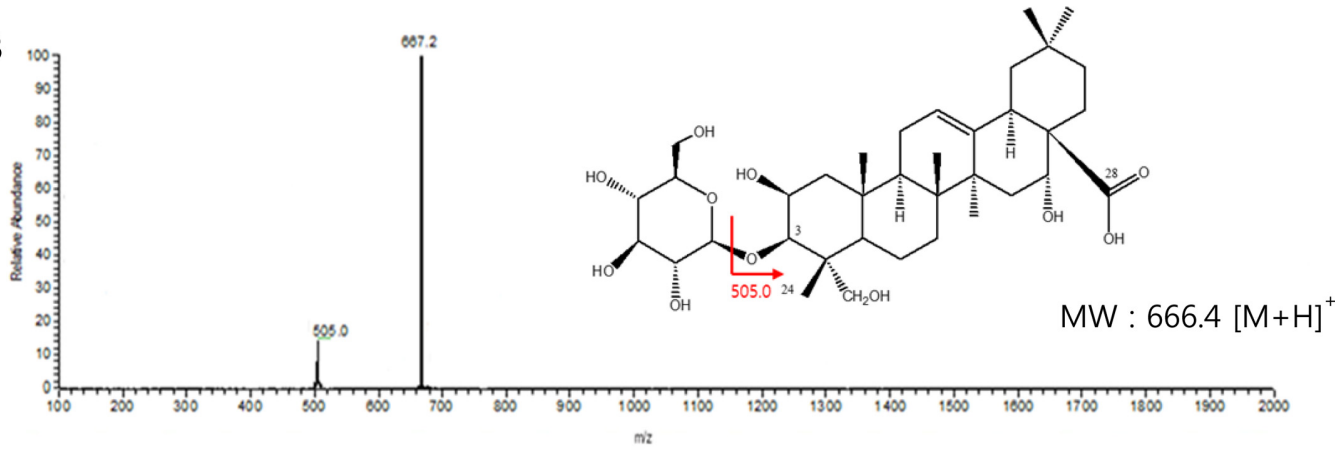

C

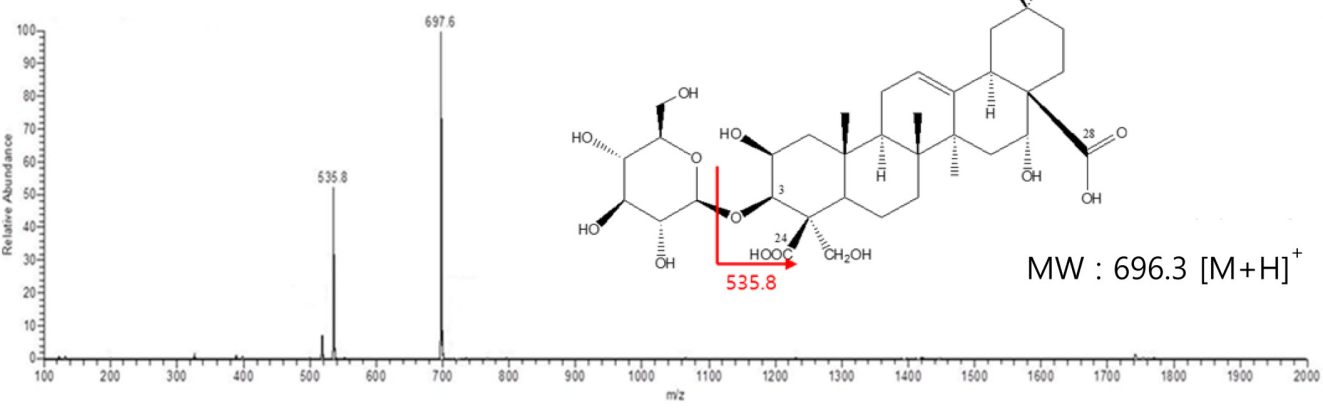

Fig. 3. LC/MS chromatograms of 3-O- $\beta$-D-glucopyranosyl platycosides. (A) 3-O- $\beta$-D-Glucopyranosyl platycodigenin. (B) 3-O- $\beta$-D-Glucopyranosylpolygalacic acid. (C) 3-O- $\beta$-D-Glucopyranosylplatyconic acid.

Hydrolytic Pathways Involved in Biotransformation of Glycosylated Platycosides into 3-O- $\beta$-D-Glucopyranosyl Platycosides

To determine the pathways involved in the biotransformation of glycosylated platycosides in Platycodi radix extract by pectinase from A. aculeatus, we carried out the biotransformation of the reagent-grade glycosylated platycosides $\mathrm{PE}$, polygalacin $\mathrm{D}_{3}$, and platyconic acid $\mathrm{A}$. In the biotransformation, $\mathrm{PE}$ was completely converted into 3-O- $\beta$-D-glucopyranosyl platycodigenin via $\mathrm{PD}$ and deapi-PD (Figs. S1A-S1C), while polygalacin $\mathrm{D}_{3}$ was completely transformed into 3-O- $\beta$-D-glucopyranosyl polygalacic acid via polygalacin $\mathrm{D}$ and intermediate 1 (Figs. S2A-S2C). Platyconic acid A was completely converted into 3-O- $\beta$-D-glucopyranosyl platyconic acid via intermediate 2 (Figs. S3A-S3C).

Deapi-PD was confirmed as an intermediate formed during the biotransformation of PE into 3-O- $\beta$-Dglucopyranosyl platycodigenin with LC/MS. The total molecular mass of deapi-PD was indicated by the main peak at $\mathrm{m} / z 1093.3[\mathrm{M}+\mathrm{H}]^{+}$in the LC/MS spectrum. The fragment peaks resulted from the cleavage of xylose, rhamnose, and arabinose at C-28 and glucose at C-3, indicating that the intermediate was deapi-PD (Fig. S1D). The intermediates 1 and 2 were also identified by LC/MS. The total molecular mass of intermediates 1 and 2 were represented by peaks at $m / z 1077.6$ and $1107.3[\mathrm{M}+\mathrm{H}]^{+}$, respectively. These results indicate that the intermediates 1 and 2 are deapi-polygalacin D and deapi-platyconic acid A (Figs. S2D and S3D). The fragment peaks of these compounds resulted from the cleavage of xylose, rhamnose, and arabinose at C-28 and glucose at C-3.

The biotransformation pathways of $\mathrm{PE}$, polygalacin $\mathrm{D}_{3}$, and platyconic acid $\mathrm{A}$ in Platycodi radix extract were determined by HPLC analysis (Figs. S3-S5). The pathways involved in the biotransformation of other glycosylated platycosides in Platycodi radix extract, including deapi- $\mathrm{PE}$, deapi- $\mathrm{PD}_{3}, \mathrm{PD}_{3}, \mathrm{PA}$, and 3 "- $O$-acetyl polygalacin $\mathrm{D}_{3}$, were investigated using reagent-grade platycosides in the HPLC chromatograms (Fig. S4). Deapi-PE, deapi- $\mathrm{PD}_{3}$, 
and $\mathrm{PD}_{3}$ as well as PA were completely converted into 3-O- $\beta$-D-glucopyranosyl platycodigenin via deapi-PD and deapi-PA, respectively. The compound 3 "-O-acetyl polygalacin $\mathrm{D}_{3}$ was completely converted into 3-O- $\beta$-Dglucopyranosyl polygalacic acid via 3"-O-acetyl polygalacin D and deapi-3"-O-acetyl polygalacin D.

Based on the HPLC data, the hydrolytic pathways of the three typical platycosides, including the platycodigenin-type platycosides deapi- $\mathrm{PE}(\mathbf{1}), \mathrm{PE}(\mathbf{2})$, deapi- $\mathrm{PD}_{3}(\mathbf{3}), \mathrm{PD}_{3}(\mathbf{4})$, deapi-PD (6), $\mathrm{PD}(7)$, and $\mathrm{PA}(\mathbf{1 0})$; polygalacic acid-type platycosides polygalacin $\mathrm{D}_{3}(\mathbf{5})$, polygalacin $\mathrm{D}(\mathbf{8})$, and 3 "- $O$-acetyl polygalacin $\mathrm{D}_{3}(\mathbf{9})$; and the platyconic acid-type platycoside platyconic acid A (11) of major glycosylated platycosides in Platycodi radix extract into 3-O- $\beta$-D-glucopyranosyl platycodigenin (12), 3-O- $\beta$-D-glucopyranosyl polygalacic acid (13), and 3$O$ - $\beta$-D-glucopyranosyl platyconic acid (14), respectively, by pectinase from A. aculeatus were newly established as shown in Fig. 4. In the hydrolytic pathways, the enzyme hydrolyzed the glucose molecules, leaving one glucose

A
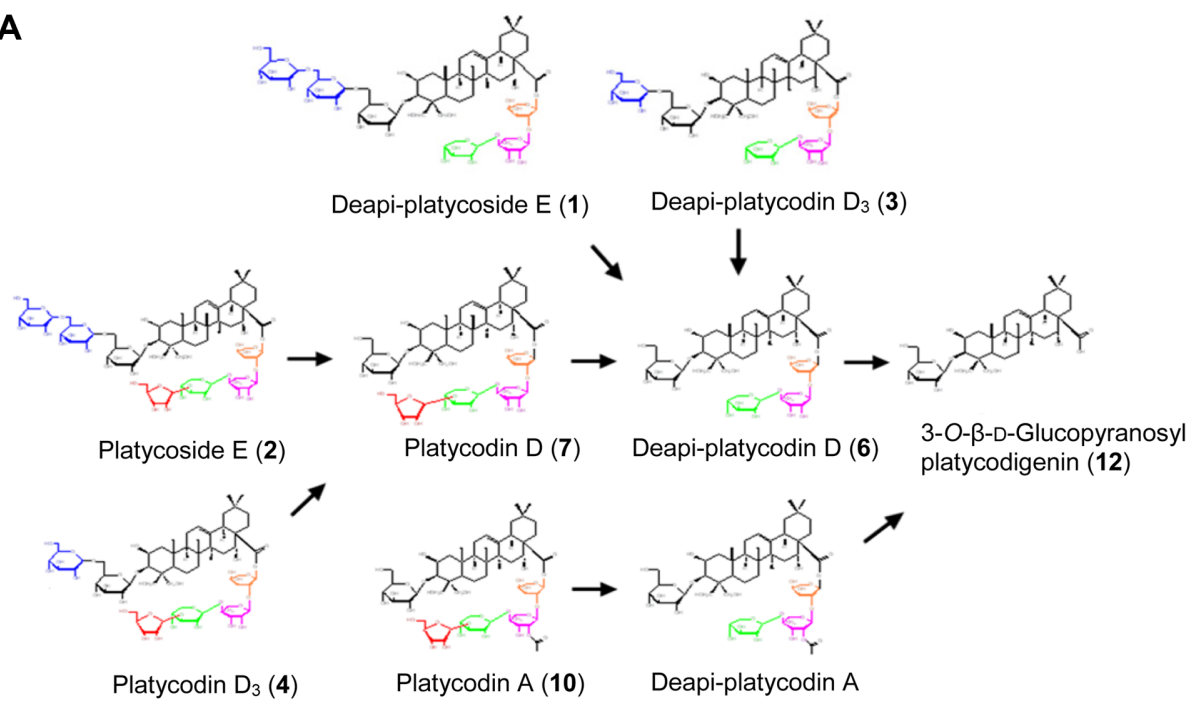

в

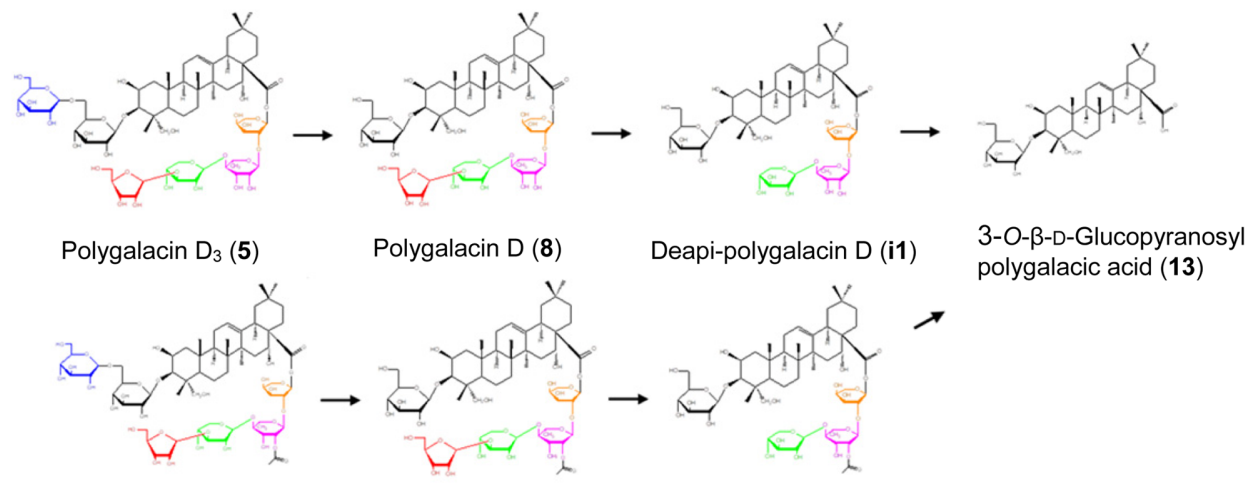

3"-O-Acetyl polygalacin $D_{3}(9) \quad 3$ "-O-Acetyl polygalacin D Deapi-3"-O-acetyl polygalacin D

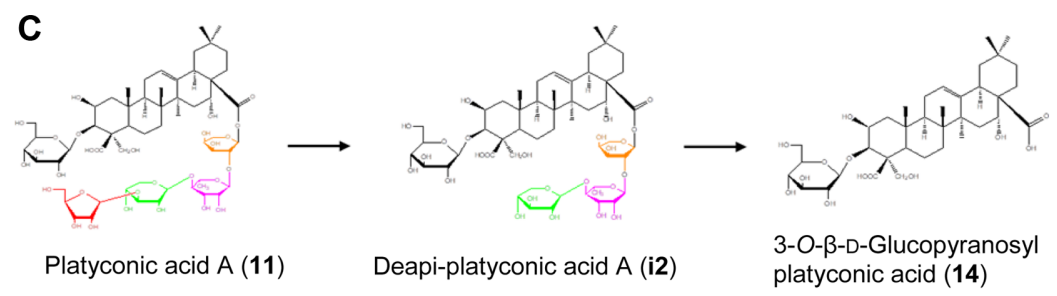

Fig. 4. Pathways involved in the biotransformation of glycosylated platycosides from Platycodi radix extract into 3-O- $\beta$-D-glucopyranosyl platycosides with pectinase from A. aculeatus. (A) Pathways involved in the biotransformation of platycodigenin-type platycosides, including deapi-platycoside $\mathrm{E}$, platycoside $\mathrm{E}$, platycodin $\mathrm{D}_{3}$, and platycodin A, into 3-O- $\beta$-D-glucopyranosyl platycodigenin. (B) Pathways involved in the biotransformation of polygalacic acid-type platycosides, including polygalacin $\mathrm{D}_{3}$ and 3"-O-acetyl polygalacin $\mathrm{D}_{3}$, into 3-O- $\beta$-D-glucopyranosyl polygalacic acid. (C) Pathways involved in the biotransformation of platyconic acid-type platycoside, platyconic acid A, into 3-O- $\beta$-Dglucopyranosyl platyconic acid. Unnumbered platycosides were not found in the HPLC chromatograms of Fig. 2. However, they were confirmed with reagent-grade platycosides (Fig. S4). 
residue at C-3 and the oligosaccharide moiety (apiofuranosyl-xylopyranosyl-rhamnopyranosyl-arabinofuranosyl residue) at $\mathrm{C}-28$

The biotransformation pathway of PE into PD by $\beta$-glucosidase of $A$. niger [14] and that of PE into deglu-PD by $\beta$-glucosidase of Caldicellulosiruptor bescii [19] were previously reported. In addition, the biotransformation pathways of glycosylated platycosides by human intestinal bacteria were suggested [20]. However, the biotransformation pathways of glycosylated platycosides in Platycodi radix extract into 3-O- $\beta$-D-glucopyranosyl platycosides by pectinase was first identified in this study.

Biotransformation of Platycoside E, Polygalacin $\mathrm{D}_{3}$, Platyconic Acid A, and Glycosylated Platycosides in Platycodi Radix Extract into 3-O- $\beta$-D-Glucopyranosyl Platycosides

The time-course reactions for the biotransformation of reagent-grade $\mathrm{PE}$ as a platycodigenin-type platycoside were performed by pectinase from A. aculeatus. After $24 \mathrm{~h}$, the enzyme completely converted $1 \mathrm{mg} / \mathrm{ml} \mathrm{PE}$ into
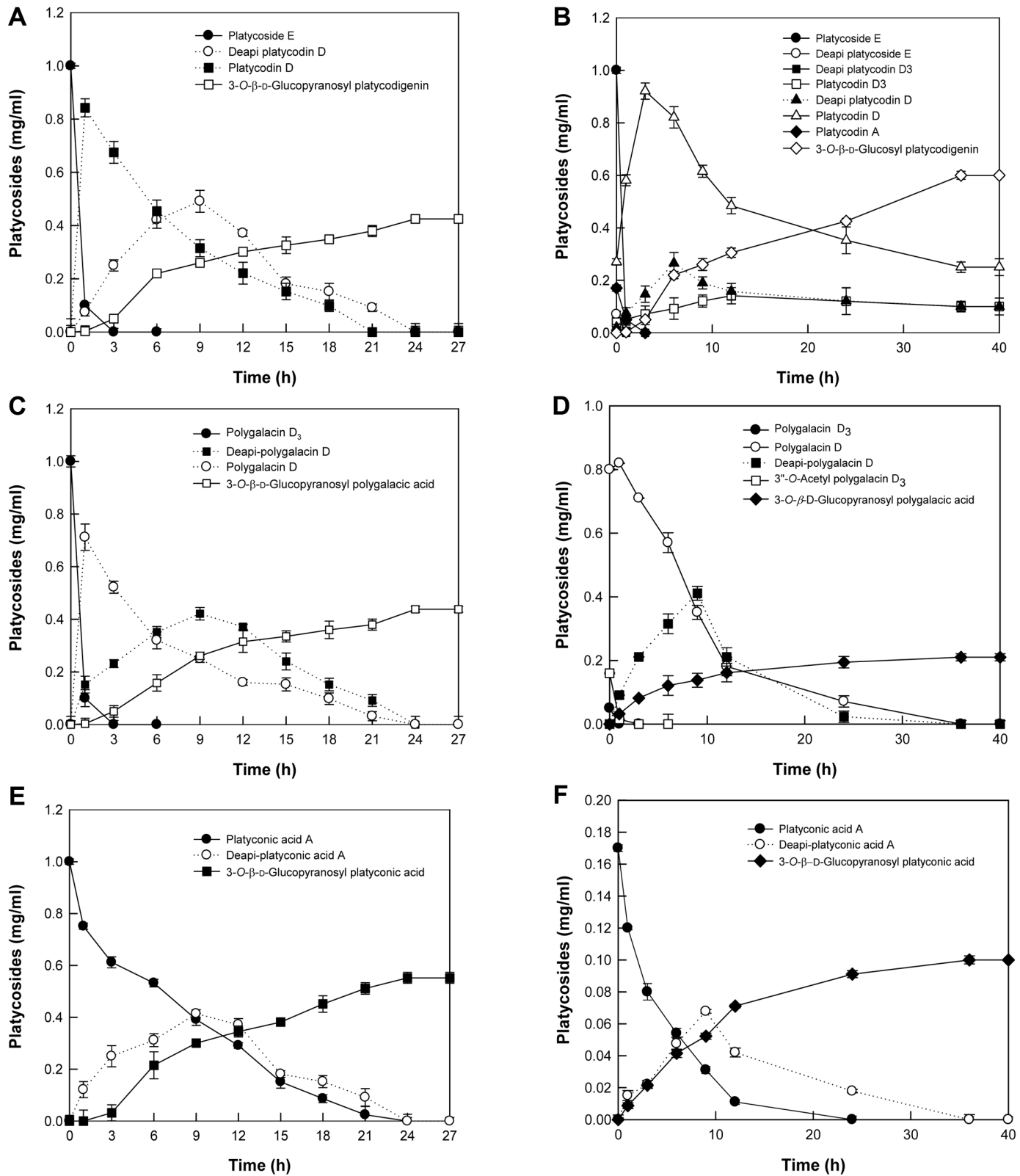

Fig. 5. Biotransformation of reagent-grade platycosides and glycosylated platycosides from Platycodi radix extract into 3-O- $\beta$-D-glucopyranosyl platycosides by pectinase from A. aculeatus. (A) Biotransformation of reagent-grade PE. (B) Biotransformation of platycodigenin-type platycosides from Platycodi radix extract. (C) Biotransformation of reagent-grade polygalacin $\mathrm{D}_{3}$. (D) Biotransformation of polygalacic acid-type platycosides from Platycodi radix extract. (E) Biotransformation of reagent-grade platyconic acid A. (F) Biotransformation of platyconic acid-type platycosides from Platycodi radix extract. 
$0.42 \mathrm{mg} / \mathrm{ml}$ 3-O- $\beta$-D-glucopyranosyl platycodigenin via $\mathrm{PD}$ and deapi-PD (Fig. 5A). The quantitative biotransformation of platycodigenin-type platycosides in Platycodi radix extract into 3 - $O$ - $\beta$-D-glucopyranosyl platycodigenin was also performed. The enzyme converted platycodigenin-type platycosides, including $0.07 \mathrm{mg} / \mathrm{ml}$ deapi-PE, $1.0 \mathrm{mg} / \mathrm{ml} \mathrm{PE}, 0.01 \mathrm{mg} / \mathrm{ml}$ deapi- $\mathrm{PD}_{3}, 0.04 \mathrm{mg} / \mathrm{ml} \mathrm{PD}{ }_{3}, 0.02 \mathrm{mg} / \mathrm{ml}$ deapi-PD, $0.27 \mathrm{mg} / \mathrm{ml} \mathrm{PD}$, and

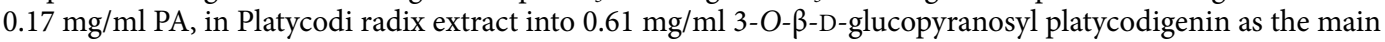
product and $0.1 \mathrm{mg} / \mathrm{ml} \mathrm{PD}_{3}, 0.11 \mathrm{mg} / \mathrm{ml}$ deapi-PD, and $0.25 \mathrm{mg} / \mathrm{ml} \mathrm{PD}$ as intermediates after $36 \mathrm{~h}$ (Fig. $5 \mathrm{~B}$ ).

The quantitative production of 3-O- $\beta$-D-glucopyranosyl polygalacic acid was attempted using the reagentgrade polygalacic acid-type polygalacin $\mathrm{D}_{3}$. After $24 \mathrm{~h}$, the enzyme completely converted $1 \mathrm{mg} / \mathrm{ml}$ polygalacin $\mathrm{D}_{3}$ into $0.43 \mathrm{mg} / \mathrm{ml} \mathrm{3-O- \beta}$-D-glucopyranosyl polygalacic acid via polygalacin D and deapi-polygalacin D (Fig. 5C). The enzyme was also used for the quantitative biotransformation of polygalacic acid-type platycosides in Platycodi radix extract, including $0.05 \mathrm{mg} / \mathrm{ml}$ polygalacin $\mathrm{D}_{3}, 0.8 \mathrm{mg} / \mathrm{ml}$ polygalacin $\mathrm{D}$, and $0.16 \mathrm{mg} / \mathrm{ml} \mathrm{3"-O}$ acetyl polygalacin $\mathrm{D}_{3}$, which were converted into $0.21 \mathrm{mg} / \mathrm{ml} 3-O-\beta$-D-glucopyranosyl polygalacic acid as a single product via $3 "-O$-acetyl polygalacin $\mathrm{D}$ and deapi-polygalacin $\mathrm{D}$ after $36 \mathrm{~h}$ (Fig. 5D).

The time-course reactions for the biotransformation of reagent-grade platyconic acid $\mathrm{A}$ as a platyconic acidtype platycoside were performed. The enzyme completely converted $1 \mathrm{mg} / \mathrm{ml}$ platyconic acid A into $0.55 \mathrm{mg} / \mathrm{ml}$ $O-\beta$-D-glucopyranosyl platyconic acid after $24 \mathrm{~h}$ via deapi-platyconic acid A (Fig. $5 \mathrm{E}$ ). The time-course reactions for the biotransformation of platyconic acid A in Platycodi radix extract into 3-O- $\beta$-D-glucopyranosyl platyconic acid were also performed. The enzyme completely converted $0.17 \mathrm{mg} / \mathrm{ml}$ platyconic acid A as a platyconic acidtype platycoside in the Platycodi radix extract into $0.1 \mathrm{mg} / \mathrm{ml} 3-O-\beta-\mathrm{D}$-glucopyranosyl platyconic acid as a single product via deapi-platyconic acid A after $36 \mathrm{~h}$ (Fig. 5F).

The quantitative enzymatic production of 3-O- $\beta$-D-glucopyranosyl platycosides was carried out for the first time in the present study. Although the biotransformation of reagent-grade platycosides resulted in the complete conversion of the substrate into 3-O- $\beta$-D-glucopyranosyl platycosides after $24 \mathrm{~h}$, we failed to observe the complete conversion of the platycosides in Platycodi radix extract after $24 \mathrm{~h}$. The retardation effect may be attributed to the inhibition of the enzyme activity by other platycosides in the extract [18].

Saponins have been reported to improve in functionality as they are deglycosylated . For example, the antiinflammatory activities of the platycodigenin-type platycosides followed the order deglu PD (three glycosides) $>$ $\mathrm{PD}$ (four glycosides) $>\mathrm{PD}_{3}$ (six glycosides) $>\mathrm{PE}$ (seven glycosides) [16] and as an antioxidant activity, the peroxynitrite-scavenging capacities followed the order platycodigenin (no glycosides) $>$ deapi-PE $>$ PD $>$ PE [21]. Thus, 3-O- $\beta$-D-glucopyranosyl platycosides (one glycoside) are expected to have high functionality and further study is needed in the functional properties of the deglycosylated platycosides.

In summary, the pectinase from $A$. auleatus converted glycosylated platycosides into the deglycosylated 3-O- $\beta$ D-glucopyranosyl platycosides by the hydrolysis of the glucose molecules at C-3, leaving one glucose residue, and the hydrolysis of the oligosaccharide moiety (apiofuranosyl-xylopyranosyl-rhamnopyranosyl-arabinofuranosyl residue) at C-28. This is the first report on the quantitative enzymatic production of 3-O- $\beta$-D-glucopyranosyl platycosides and the establishment of the biotransformation pathways.

\section{Acknowledgments}

This study was supported by the Individual Basic Science \& Engineering Research Program through the National Research Foundation grant funded by the Ministry of Science and ICT, Republic of Korea (NRF2017R1D1A1B03033762) and by Konkuk University Researcher Fund in 2019.

\section{Conflict of Interest}

The authors have no financial conflicts of interest to declare.

\section{References}

1. Zhao HL, Harding SV, Marinangeli CP, Kim YS, Jones PJ. 2008. Hypocholesterolemic and anti-obesity effects of saponins from Platycodon grandiflorum in hamsters fed atherogenic diets. J. Food Sci. 73: H195-200.

2. Chung JW, Noh EJ, Zhao HL, Sim JS, Ha YW, Shin EM, et al. 2008. Anti-inflammatory activity of prosapogenin methyl ester of platycodin D via nuclear factor-kappaB pathway inhibition. Biol. Pharm. Bull. 31: 2114-2120.

3. Jang KJ, Kim HK, Han MH, Oh YN, Yoon HM, Chung YH, et al. 2013. Anti-inflammatory effects of saponins derived from the roots of Platycodon grandiflorus in lipopolysaccharidestimulated BV2 microglial cells. Int. J. Mol Med. 31: 1357-1366.

4. Halliwell B. 2006. Oxidative stress and neurodegeneration: where are we now? J. Neurochem. 97: 1634-1658.

5. Park S, Yoo J, Kim H, Choi Y, Choi H, Song J. 2013. The physiochemical characteristics and anti-oxidant activity of extracts of Platycodon grandiflorus (Jacquin) A. De Candolle. Planta Med. 79: 1267-1268.

6. Choi YH, Kim YS, Yeo SJ, Roh SH, Jeong YC, Kang JS, et al. 2008. Ameliorating effect of balloon flower saponin on the ethanolinduced memory impairment in mice. Phytother. Res. 22: 973-976.

7. Yoo KY, Park OK, Hwang IK, Li H, Ryu SY, Kang IJ, et al. 2008. Induction of cell proliferation and neuroblasts in the subgranular zone of the dentate gyrus by aqueous extract from Platycodon grandiflorum in middle-aged mice. Neurosci. Lett. 444: 97-101.

8. Chun J, Joo EJ, Kang M, Kim YS. 2013. Platycodin D induces anoikis and caspase-mediated apoptosis via p38 MAPK in AGS human gastric cancer cells. J. Cell Biochem. 114: 456-470.

9. Park CS, Yoo MH, Noh KH, Oh DK. 2010. Biotransformation of ginsenosides by hydrolyzing the sugar moieties of ginsenosides using microbial glycosidases. Appl. Microbiol. Biotechnol. 87: 9-19.

10. Shin KC, Oh DK. 2016. Classification of glycosidases that hydrolyze the specific positions and types of sugar moieties in ginsenosides. Crit. Rev. Biotechnol. 36: 1036-1049.

11. Li W, Zhao LC, Wang Z, Zheng YN, Liang J, Wang H. 2012. Response surface methodology to optimize enzymatic preparation of deapio-platycodin D and platycodin D from radix platycodi. Int. J. Mol. Sci. 13: 4089-4100. 
12. Jeong EK, Ha IJ, Kim YS, Na YC. 2014. Glycosylated platycosides: Identification by enzymatic hydrolysis and structural determination by LC-MS/MS. J. Sep. Sci. 37: 61-68.

13. Ha IJ, Kang M, Na YC, Park Y, Kim YS. 2011. Preparative separation of minor saponins from platycodi radix by high-speed countercurrent chromatography. J. Sep. Sci. 34: 2559-2565.

14. Ahn HJ, You HJ, Park MS, Johnston TV, Ku S, Ji GE. 2018. Biocatalysis of platycoside E and platycodin D3 using fungal extracellular beta-glucosidase responsible for rapid platycodin D Production. Int. J. Mol. Sci. 19: 2671.

15. Wie HJ, Zhao HL, Chang JH, Kim YS, Hwang IK, Ji GE. 2007. Enzymatic modification of saponins from Platycodon grandiflorum with Aspergillus niger. J. Agric. Food Chem. 55: 8908-8913.

16. Kang SH, Kim TH, Shin KC, Ko YJ, Oh DK. 2019. Biotransformation of food-derived saponins, platycosides, into deglucosylated saponins including deglucosylated platycodin D and their anti-inflammatory activities. J. Agr. Food Chem. 67: 1470-1477.

17. Tang ZY, Hou YY, Hu XY, Liu AN, Yau LF, Tong TT, et al. 2017. Metabolite identification and pharmacokinetic study of platycodi radix (Jiegeng) in vivo. Rsc. Adv. 7: 37459-37466.

18. Son JW, Kim HJ, Oh DK. 2008. Ginsenoside Rd production from the major ginsenoside Rb(1) by beta-glucosidase from Thermus caldophilus. Biotechnol. Lett. 30: 713-716.

19. Kil TG, Kang SH, Kim TH, Shin KC, Oh DK. 2019. Enzymatic biotransformation of balloon flower root saponins into bioactive platycodin D by deglucosylation with Caldicellulosiruptor bescii beta-glucosidase. Int. J. Mol. Sci. 20: 3854.

20. Nyakudya E, Jeong JH, Lee NK, Jeong YS. 2014. Platycosides from the Roots of Platycodon grandiflorum and their health benefits. Prev. Nutr. Food Sci. 19: 59-68.

21. Ryu CS, Kim CH, Lee SY, Lee KS, Choung KJ, Song GY, et al. 2012. Evaluation of the total oxidant scavenging capacity of saponins isolated from Platycodon grandiflorum. Food Chem. 132: 333-337. 